Review Article

\title{
An Integrative Review of the Methods Used to Research the Prevalence of Violence against Women in Pakistan
}

\author{
Farhana Irfan Madhani, ${ }^{1}$ Catherine Tompkins, ${ }^{1}$ Susan M. Jack, ${ }^{2}$ and Anita Fisher ${ }^{1}$ \\ ${ }^{1}$ School of Nursing, McMaster University, 1280 Main Street West, Hamilton, ON, Canada L8S 4K1 \\ ${ }^{2}$ School of Nursing, Clinical Epidemiology \& Biostatistics, McMaster University, 1280 Main Street West, \\ Hamilton, ON, Canada L8S 4K1 \\ Correspondence should be addressed to Farhana Irfan Madhani; madhanfi@mcmaster.ca
}

Received 19 February 2014; Accepted 11 July 2014; Published 7 September 2014

Academic Editor: Ann M. Mitchell

Copyright (C) 2014 Farhana Irfan Madhani et al. This is an open access article distributed under the Creative Commons Attribution License, which permits unrestricted use, distribution, and reproduction in any medium, provided the original work is properly cited.

\begin{abstract}
This paper is a report of an integrative review conducted to assess the methodological and ethical strategies used to protect participants and researchers in conducting violence against women (VAW) studies in Pakistan. The measurement of the prevalence of violence against women in Pakistan is challenging for researchers given the cultural norms and the traditional role of women. Lack of methodological rigor in addressing the concerns can result in underreporting of violence, create physical and emotional risk for the participants, interviewers, and researchers, and impose threats to internal and external validity of VAW studies. Using Whittemore and Knafl's process for conducting an integrative review, 11 studies published between 1999 and 2012, reporting on prevalence, experiences, and factors associated with violence in a marital relationship were analyzed. Overall, studies reveal an underreporting of exposure to violence and threats to women and interviewers' safety in the conduct of such studies, both of which present threats to study rigor. The utilization of WHO ethical and safety recommendations to guide VAW studies in this context should be considered.
\end{abstract}

\section{Introduction}

Over the past three decades, there has been increasing international attention to measuring rates of violence against women (VAW) in different countries [1]. Some of these studies also focus on the development and evaluation of identification and intervention strategies. Researchers who examine gender-based violence to better identify the extent of violence, its causes, consequences, and subsequent interventions are faced with several challenges $[2,3]$. For example, the estimated prevalence of VAW among, between and within countries, regions and cultures is hampered due to variations in how VAW is conceptualized and defined and how the studies are implemented $[4,5]$. Moreover, researchers have identified that VAW research entails a particular set of risks and concerns related to how participants are recruited and how violence is measured, compared, and reported [3]. Lack of methodological consistency in addressing these concerns can result in underreporting of violence and may entail risks to the mental wellbeing of the participants, as well as the researcher [4] and impose threats to internal and external validity of VAW studies $[2,6]$. In response to these issues, the World Health Organization (WHO) developed ethical and safety recommendations to guide in conducting future studies concerning VAW [7].

VAW is an important issue in Pakistan although there are no reliable statistics on the overall prevalence or incidence given the lack of reliable national surveys on this topic [2]. However, there have been many preliminary surveys conducted to estimate the rate of abuse among women. These surveys suggest that VAW is highly prevalent in Pakistan, but researchers in the field of VAW studies believe that it may be underreported $[8,9]$. This is likely because VAW is considered a private matter, deeply rooted in cultural beliefs and attitudes, particularly in the strong patriarchal ideas that dominate societal norms and behavior [10]. In addition, marriage vows are interpreted as granting the man the right to control his wife's life [11], thus making women 
socially, economically, and emotionally dependent on their husbands. Similarly, cultural practices and social norms may lead to the belief that VAW is acceptable, thereby preventing women from disclosing their abuse experiences [2]. In some parts of the country, restrictive cultural norms reduce a woman's movement and interaction with the outside world unless accompanied by a male family member [12]. Generally, women may not invite outsiders into the home while their male or senior family members are absent [2]. These realities present significant methodological and ethical considerations for researchers who conduct studies focusing on VAW.

There is no universally agreed upon definition of VAW, as the term varies within regional and cultural contexts [4]. This review used the definition derived from the United Nations General Assembly (UNGA) declaration on the elimination of violence against women which defines VAW as "any act of gender-based violence that results in, or is likely to result in, physical, sexual or psychological harm or suffering to women, including threats of such acts, coercion or arbitrary deprivation of liberty, whether occurring in public or private life" [13, p.3]. Intimate partner violence (IPV), which is one of the most common phenomena of VAW within a marital relationship in the Pakistani cultural context, was the focus of this review. The significant growing burden of increased VAW demands the attention of health care practitioners (HCPs), particularly nurses, as they play a significant role in health promotion and illness prevention. The paper will conclude with a summary of the methodological limitations and proposed recommendations for practice, education, and researching VAW.

\section{The Review}

2.1. Aim. The purpose of this review was to identify and assess the strategies used to conduct VAW studies in Pakistan. The following two broad research questions were addressed. (1) What are the methodological strategies researchers used in Pakistani VAW studies for sample selection, recruitment, data collection, and data analysis? And (2) what ethical challenges and subsequent strategies to overcome these challenges are identified in VAW studies from Pakistan?

2.2. Design. Whittemore and Knafl's [14] updated integrative review framework guided the analysis. This method is appropriate for systematically and rigorously reviewing and synthesizing the VAW literature. It incorporates a method of analyzing research from diverse empirical and theoretical sources and delineates a systematic framework that enhances the rigor of the integrative review process [14]. The integrative review methodology begins with identifying the problem and its related concepts in order to facilitate data extraction from the primary sources. It then outlines well-defined literature search strategies, including search terms and inclusion and exclusion criteria to assess the relevance of primary sources. Next, data evaluation is employed, whereby the quality of the primary studies is evaluated against the identified gold standard measure. Once the maximum number of eligible primary sources is identified, studies are organized into groups and subgroups for the purpose of data extraction and reduction. The data are then arranged in a format to visualize patterns, relationships, and variation among the concepts. This data reduction step supports the iterative analysis methods of qualitative research. Finally, conclusions are drawn and verified with the intent that the depth and breadth of the relevant literature are captured in a logical chain of evidence (Tables 1 and 2).

2.3. The Literature Search. Electronic searching, ancestral searching, hand searching, and citation tracking were carried out within CINAHL, Medline, PubMed, PsycInfo, Global health, OVID, Web of Science databases. Since the electronic copies from the archives of two journals could not be available, therefore Journal of Pakistan Medical Association and Pakistan Journal of Medical Sciences were hand-searched. During the search process several terms were combined to form key terms combination (Table 3). For example, first, there is the category referring to victim such as partner, wife, or women, the second category refers to various synonyms for violence, the third category refers to multiple forms of violence, and finally the fourth category indicates location or placement where the studies were carried out such as Pakistan or different provinces of Pakistan. The combination of all the four categories was used to identify the potentially relevant results from the databases. Empirical quantitative, qualitative, and mixed methods research carried out during 1999 and 2012 originally published in English and in a scientific journal was selected. Only those studies were selected where the research participants were women from Pakistan. The selected year beginning from 1999 was deliberately chosen based on the WHO protocol and ethical and safety recommendations for research on domestic violence against women guidelines first introduced in the years 1997 and 1999, respectively [7, 15]. A detailed search strategy led 84 studies. After removing the duplicate studies and filter out for inclusion and exclusion criteria, 18 relevant studies were identified. A component of results of two studies published elsewhere narrowed down the search to 16 studies.

2.4. Data Evaluation. All 16 studies were critically appraised prior to being included in any analysis. Quantitative studies were evaluated using two critical appraisal tools: (1) quality assessment tool for quantitative studies (Effective Public Health Practice Project (EPHPP) Guideline), [16]; and (2) guidelines for critiquing quantitative research report [17]. Qualitative studies were graded based upon the appraisal standards of Letts and colleagues [18], whereas mixed methods research (MMR) followed Mixed Methods Appraisal Tool [19]. Five studies failed to adequately meet the selection criteria and were therefore discarded. Eleven studies were included in the analysis; eight were quantitative, two were qualitative, and one was MMR.

2.5. Data Reduction, Representation, and Comparison. During the data reduction stage, data were extracted and represented numerically and textually [14]. To facilitate the iterative comparison and interpretation, data were reduced according to specific "issues, variables, or sample characteristics" [14, p. 550]. The research questions were answered 
TABLE 1: Summary of methodological research strategies among the studies reviewed.

(a)

\begin{tabular}{|c|c|c|c|c|}
\hline Strategies & Ali et al. [20] & $\begin{array}{l}\text { Ali and } \\
\text { Bustamante-Gavino [26] }\end{array}$ & Andersson et al. [21] & Farid et al. [22] \\
\hline \multicolumn{5}{|l|}{ Sample selection: } \\
\hline Study setting & Urban & Urban & Urban and rural & Urban \\
\hline Study sample & Married, 25-60 yrs & $\begin{array}{l}\text { Married, } 15-45 \text { yrs, at } \\
\text { least } 2 \text { children }\end{array}$ & $\begin{array}{l}\text { Women married or not } \\
>14 \mathrm{yrs}\end{array}$ & $\begin{array}{l}\text { Recently deliver, } \\
15-49 \text { yrs, living with } \\
\text { partner }\end{array}$ \\
\hline Sampling frame & $\begin{array}{l}\text { Multistage } \\
\text { randomization }\end{array}$ & Purposive, nonrandom & Stratified cluster random & Random \\
\hline Sample size & 800 women & 400 women & 23430 & 500 \\
\hline \multicolumn{5}{|l|}{ Recruitment: } \\
\hline Recruitment site & 2 low SES communities & 5 low SES communities & 100 communities & $\begin{array}{l}4 \text { tertiary care public } \\
\text { hospitals }\end{array}$ \\
\hline Recruitment strategy & $\begin{array}{l}\text { Midwives/health } \\
\text { workers }\end{array}$ & $\mathrm{CHW}^{*}$ & $\mathrm{CHW}^{*}$ & Absent \\
\hline Response (refusal) rate (\%) & $93.7(6.3)$ & $92.5(7.5)$ & (3) & Absent \\
\hline \multicolumn{5}{|l|}{ Data collection: } \\
\hline Data source & Survey interview & Survey interview & S. interview/FGD* & Survey interview \\
\hline Data collection tool & $\begin{array}{l}\text { Multicountry } \\
\text { Study on Women's } \\
\text { Health and Life } \\
\text { Experiences } \\
\text { Questionnaire }\end{array}$ & $\begin{array}{l}\text { Designed based on } \\
\text { FGD* }\end{array}$ & $\begin{array}{l}\text { Designed for survey and } \\
\text { FGD }^{*}\end{array}$ & $\begin{array}{l}\text { WHO-DV* module } \\
\text { (modified version) }\end{array}$ \\
\hline Tool validity & Assured & Assured & Assured & Assured \\
\hline Interviewers/training & Experienced/extensive & Experienced/extensive & Experienced/extensive & Absent/extensive \\
\hline Privacy during interview & $\begin{array}{l}\text { Home, nearby school, } \\
\text { NGO facility }\end{array}$ & In absence of husband & $\begin{array}{l}\text { In absence of male and } \\
\text { senior women }\end{array}$ & Outside visiting hours \\
\hline Data quality control & $\begin{array}{l}\text { Reinterviewed 5\% } \\
\text { randomly selected } \\
\text { participants }\end{array}$ & $\begin{array}{l}\text { Data cleaning, } \\
\text { validation, double } \\
\text { entered }\end{array}$ & $\begin{array}{l}\text { Data cleaning, } \\
\text { validation, double } \\
\text { entered }\end{array}$ & Implicit \\
\hline \multicolumn{5}{|l|}{ Data analysis: } \\
\hline $\begin{array}{l}\text { Methods of } \\
\text { analysis/limitations }\end{array}$ & Explicit & Explicit & Explicit & Explicit \\
\hline Interpretation of finding & Explicit & Explicit & Explicit & Explicit \\
\hline
\end{tabular}

${ }^{*}$ CHW: community health worker, FGD: focus group discussion, WHO: World Health Organization, DV: domestic violence.

(b)

\begin{tabular}{|c|c|c|c|c|}
\hline Strategies & Fikree et al. [23] & Fikree and Bhatti [8] & Hussain and Khan [28] & Karmaliani et al. [24] \\
\hline \multicolumn{5}{|l|}{ Sample selection: } \\
\hline Study setting & Urban & Urban & Urban & Urban \\
\hline Study sample & $\begin{array}{l}\text { Recently deliver } \\
\text { women }\end{array}$ & $\begin{array}{l}\text { Married women living } \\
\text { with husband }\end{array}$ & $\begin{array}{l}\mathrm{CKI}^{*} \text { and women } \\
\text { experiencing violence }\end{array}$ & $\begin{array}{l}\text { Pregnant women } \\
\text { (20-26 wks gestation) }\end{array}$ \\
\hline Sampling frame & Random & Convenience & $\begin{array}{l}\mathrm{CKI}^{*} \text { : snowball } \\
\text { women: purposive }\end{array}$ & Random \\
\hline Sample size & 300 & 150 & $\begin{array}{l}8 \text { key informants } \\
3 \mathrm{FGD}^{*}: 23 \text { women } \\
\text { in-depth interview: } 10 \\
\text { women }\end{array}$ & 1324 women \\
\hline \multicolumn{5}{|l|}{ Recruitment: } \\
\hline Recruitment site & $\begin{array}{l}\text { A large tertiary public } \\
\text { hospital }\end{array}$ & Outpatient clinics & $\begin{array}{l}2 \text { middle and lower middle } \\
\text { SES* communities }\end{array}$ & $\begin{array}{l}\text { Low to middle SES* } \\
\text { community }\end{array}$ \\
\hline Recruitment strategy & Absent & Absent & CKI & LHW $^{*}$ \\
\hline $\begin{array}{l}\text { Response (refusal) rate } \\
(\%)\end{array}$ & $(<1 \%)$ & Absent & Absent & $96.7 \%$ \\
\hline
\end{tabular}


(b) Continued.

\begin{tabular}{|c|c|c|c|c|}
\hline Strategies & Fikree et al. [23] & Fikree and Bhatti [8] & Hussain and Khan [28] & Karmaliani et al. [24] \\
\hline \multicolumn{5}{|l|}{ Data collection: } \\
\hline Data source & Survey interview & Survey interview & $\begin{array}{l}\text { FGD }^{*}, \mathrm{CKI}^{*} \text {, and in-depth } \\
\text { interviews }\end{array}$ & Survey interview \\
\hline Data collection tool & Conflict Tactic Scale & Designed for the study & $\begin{array}{l}\text { Semistructured } \\
\text { questionnaire designed }\end{array}$ & $\begin{array}{l}\text { WHO-DV* module } \\
\text { (modified) }\end{array}$ \\
\hline Tool validity & Assured & Assured & Assured & Assured \\
\hline Interviewers/training & Absent & Absent & Implicit & Experienced/extensive \\
\hline Privacy during interview & Absent & Assured & CKI's residence & Research clinic \\
\hline Data quality control & Implicit & Absent & Implicit & $\begin{array}{l}\text { Data cleaning, double } \\
\text { entered }\end{array}$ \\
\hline \multicolumn{5}{|l|}{ Data analysis: } \\
\hline $\begin{array}{l}\text { Methods of } \\
\text { analysis/limitations }\end{array}$ & Explicit & Explicit & Explicit & Explicit \\
\hline Interpretation of finding & Explicit & Explicit & Explicit & Explicit \\
\hline
\end{tabular}

${ }^{*}$ CKI: community key informants, DV: domestic violence, FGD: focus group discussion, LHW: Lady Health Worker, SES: Socioeconomic Status, WHO: World Health Organization.

(c)

\begin{tabular}{|c|c|c|c|}
\hline Strategies & Naeem et al. [25] & Rabbani et al. [29] & Shaikh [27] \\
\hline \multicolumn{4}{|l|}{ Sample selection: } \\
\hline Study setting & Urban & Urban & Urban \\
\hline Study sample & Married women & $\begin{array}{l}\mathrm{CKI}^{*} \text { and women } \\
\text { experiencing violence }\end{array}$ & Married women \\
\hline Sampling frame & Random & $\begin{array}{l}\mathrm{CKI}^{*} \text { and } \mathrm{FGD}^{*} \text { : purposive } \\
\text { Survey interview: } \\
\text { convenience }\end{array}$ & Convenience \\
\hline Sample size & 657 & $\begin{array}{l}8 \mathrm{CKI}^{*} \\
13 \mathrm{FGD}^{*}: 8 \text { women and } 5 \\
\text { men } \\
\text { in-depth interview: } 108 \\
\text { women }\end{array}$ & 216 women \\
\hline \multicolumn{4}{|l|}{ Recruitment: } \\
\hline Recruitment site & Women from $\mathrm{PHC}^{*}$ clinic & Absent & OPC $^{*}$ of public hospital \\
\hline Recruitment strategy & Absent & $\mathrm{CHW}^{*}$ and $\mathrm{CKI}^{*}$ & Absent \\
\hline Response (refusal) rate (\%) & $(18.6 \%)$ & Absent & $70.3 \%$ \\
\hline \multicolumn{4}{|l|}{ Data collection: } \\
\hline Data source & Survey interview & $\begin{array}{l}\text { CKI, FGD, and in-depth } \\
\text { interview }\end{array}$ & Survey interview \\
\hline Data collection tool & WEB and DAC & $\begin{array}{l}\text { Semistructured } \\
\text { questionnaire designed } \\
\text { based on CKIs' interview } \\
\text { and FGD }\end{array}$ & $\begin{array}{l}\text { Design structured } \\
\text { questionnaire }\end{array}$ \\
\hline Tool validity & Assured & Absent & Absent \\
\hline Interviewers/training & Experienced/extensive & Absent/extensive & Implicit \\
\hline Privacy during interview & Absent & CKIs' residence & Assured \\
\hline Data quality control & Implicit & $\begin{array}{l}\text { Data cleaning, validation, } \\
\text { double entered }\end{array}$ & Absent \\
\hline \multicolumn{4}{|l|}{ Data analysis: } \\
\hline Methods of analysis/limitations & Explicit & Explicit & Explicit \\
\hline Interpretation of finding & Explicit & Explicit & Implicit \\
\hline
\end{tabular}

${ }^{*}$ CHW: community health worker, CKI: community key informants, FGD: focus group discussion, OPC: outpatient clinic, PHC: primary health care. 
TABLE 2: Summary of ethical and safety measures among the studies reviewed.

\begin{tabular}{|c|c|c|c|c|c|c|}
\hline $\begin{array}{l}\text { Lead author } \\
\text { (year) }\end{array}$ & $\begin{array}{l}\text { Ethics } \\
\text { approval }\end{array}$ & $\begin{array}{l}\text { Informed } \\
\text { consent }\end{array}$ & $\begin{array}{l}\text { Participant's } \\
\text { safety/confidentiality }\end{array}$ & $\begin{array}{l}\text { Interviewer's } \\
\text { safety/support }\end{array}$ & $\begin{array}{l}\text { Data } \\
\text { safety }\end{array}$ & $\begin{array}{l}\text { Acknowledge } \\
\text { WHO } \\
\text { recommendation }\end{array}$ \\
\hline Ali (2011) [20] & Assured & Written & $\begin{array}{l}\text { (i) One eligible woman/household } \\
\text { (ii) Referral and support to identified cases } \\
\text { (iii) Known interviewers }\end{array}$ & Implicit & Implicit & Explicit \\
\hline Ali (2007) [26] & Assured & Verbal & $\begin{array}{l}\text { (i) Data collected for other health issues } \\
\text { (ii) Known interviewers }\end{array}$ & Implicit & Absent & Explicit \\
\hline $\begin{array}{l}\text { Andersson } \\
(2010)[21]\end{array}$ & Assured & Obtained & $\begin{array}{l}\text { (i) Interview all eligible women } \\
\text { (ii) Referral and support to identified cases } \\
\text { (iii) Neutral interviewers } \\
\text { (iv) Participants asked not to share interview } \\
\text { details with family }\end{array}$ & Implicit & Implicit & Explicit \\
\hline $\begin{array}{l}\text { Farid (2008) } \\
{[22]}\end{array}$ & Assured & Obtained & Implicit & Implicit & Absent & Explicit \\
\hline $\begin{array}{l}\text { Fikree }(2006) \\
{[23]}\end{array}$ & Absent & Absent & Implicit & Absent & Absent & Absent \\
\hline Fikree (1999) [8] & Absent & Obtained & Implicit & Absent & Absent & Absent \\
\hline $\begin{array}{l}\text { Hussain (2008) } \\
{[28]}\end{array}$ & Absent & Absent & Implicit & Absent & Absent & Absent \\
\hline $\begin{array}{l}\text { Karmaliani } \\
(2008)[24]\end{array}$ & Assured & Written & $\begin{array}{l}\text { (i) One eligible woman/house hold, } \\
\text { (ii) Referral and extra support } \\
\text { (iii) Neutral interviewers } \\
\text { (iv) Participants asked not to share interview } \\
\text { details with family }\end{array}$ & $\begin{array}{l}\text { debriefing and } \\
\text { support }\end{array}$ & Explicit & Explicit \\
\hline $\begin{array}{l}\text { Naeem (2008) } \\
{[25]}\end{array}$ & Absent & Obtained & Implicit & Absent & Absent & Absent \\
\hline $\begin{array}{l}\text { Rabbani (2008) } \\
{[29]}\end{array}$ & Assured & Verbal & Implicit & Implicit & Explicit & Explicit \\
\hline $\begin{array}{l}\text { Shaikh (2003) } \\
\text { [27] }\end{array}$ & Absent & Verbal & Implicit & Absent & Absent & Absent \\
\hline
\end{tabular}

TABLE 3: Key term search.

\begin{tabular}{lccc}
\hline First & Second & Third & Fourth \\
\hline Partner & Violence & Prevalence & Pakistan \\
Intimate partner & Abuse & Verbal & Sindh \\
Family & Battered & Physical & Punjab \\
Marital & Violence against women & Psychological & Baluchistan \\
Wife & Domestic violence & Emotional & Khyber-pakhtunkhwa \\
Women & & Sexual & \\
Female & & & \\
\hline
\end{tabular}

by the systematic comparison of reduced data from primary sources. Sample data were reduced based on the selected research strategies (e.g., sampling, recruitment, and data collection and analysis) and ethical and safety recommendations. Reorganized and reduced data formed the basis for the analysis (Tables 1 and 2). Details are documented as extensive (considered and mentioned), implicit (mentioned but not extensively), or absent (not mentioned).

\section{Results}

The comprehensive synthesis of the integrative review includes overall quality of the selected studies for the integrative review and a discussion of the answers to the research questions based on the analysis. Out of the 11 studies included in analysis, 6 studies reported on prevalence and magnitude of violence and associated factors, of which 4 studies were specific to experiences of violence during pregnancy. Four studies also examined different forms of violence, and 1 was specific to physical abuse and its association with anxiety and depression. Qualitative studies detailed on experiences of sexual violence and its effect on marital relationship, experiences of abuse, and factors related to disclosure and coping mechanisms.

3.1. Overall Quality of the Selected Studies. Quality of the primary studies selected for this review was determined at two levels. First, the studies were evaluated against the generic 
TABLE 4: Description of WHO ethical and safety guidelines and recommended actions.

\begin{tabular}{ll}
\hline Guidelines & Recommended actions \\
\hline Methodological sound research & $\begin{array}{l}\text { Ethical Review Board approval, measures to prevent underreporting, pretesting and } \\
\text { piloting of research tool, careful selection and training of female interviewers, monitoring } \\
\text { of study quality. }\end{array}$ \\
\hline Respondent and interviewer's safety & $\begin{array}{l}\text { Informed consent, interview in private setting, study framed on women's health, life } \\
\text { experiences and family relations, one woman per household, logistic planning for } \\
\text { respondent and interviewer's safety, measures to reduce emotional stress of interviewers } \\
\text { (periodic debriefing). }\end{array}$ \\
\hline Interviewers & $\begin{array}{l}\text { Careful selection of interviewers, interviewers should not conduct interviews in their } \\
\text { own community, supportive and nonjudgmental attitude of interviewers, special } \\
\text { consideration of content and process of training (issues related to VAW and measure to } \\
\text { reduce biases, fear, and stereotype), special attention to questioning techniques, measures } \\
\text { to end interview in positive way and discourage interviewer in counseling activities. }\end{array}$ \\
\hline Maintaining confidentiality & $\begin{array}{l}\text { Use of unique code instead of respondent's name on research questionnaire, measures for } \\
\text { data safety (data kept in a locked cabinet with limited access), and proper disposal at the } \\
\text { completion of research. }\end{array}$ \\
\hline Referral & $\begin{array}{l}\text { Provision of resource list and educational material to all informants, availability of } \\
\text { trained counselor in the research team. }\end{array}$ \\
\hline Study implications & $\begin{array}{l}\text { Correct interpretation and dissemination of study findings to study participants, national } \\
\text { and international publication, policy maker, and advisory group. Follow finding and } \\
\text { actions for positive change and not to further stigmatize certain group. }\end{array}$ \\
\hline design & $\begin{array}{l}\text { Ensure to follow ethical and methodological guidelines if integrating violence question } \\
\text { into survey designed for other purposes. }\end{array}$ \\
\hline Reftions in other survey &
\end{tabular}

Reference: World Health Organization [7].

methodological criteria as discussed in the data evaluation stage. Next, the selected studies were graded against the WHO [7] ethical and safety recommendations for research on VAW (Table 4). Results of the overall quality of the selected studies show that 3 were strong studies, 2 were moderately strong, 4 studies were moderate, and only 2 studies ranged from weak to moderate (Table 5).

3.2. Analysis of Research Questions. Answering the research questions formed the framework for this integrative review.

What are the methodological strategies researchers use in Pakistani VAW studies for sample selection, recruitment, data collection, and data analysis?

Sample Selection. Among the studies reviewed, great variation existed in the sampling strategies and study populations employed (Table 1). Across the quantitative studies, probability random sampling was predominantly used [8, 20-25]. However, two quantitative studies employed nonprobability sampling; one used purposive [26] and one used convenience [27] sampling. The qualitative design of MMR by Andersson and colleagues [21] exploring barriers in reporting violence incorporated snowball sampling for in-depth interviews. Sample size among quantitative studies ranged widely, from 150 [8] to 23,430 women [21]. The qualitative studies sampled women who experienced abuse as reported by self or identified by community key informants [28, 29]. Convenience and snowball sampling strategies were the common sampling features among qualitative studies. Sample size also varied and ranged from 23 [28] to 108 women [29]. Among all the studies reviewed, variations in study populations included age range, marital status/living arrangements [20, 21, 26], and circumstances such as pregnancy [22-24] and parenthood [26]. Across all studies, participants' ages ranged from 15 years [26] to 60 years [20]. With exception of the Andersson and colleagues population survey, the majority of the studies were conducted within urban settlements [21].

Recruitment. Although it is commonly known that restrictive attitudes concerning women's movements and decisionmaking in Pakistani society makes recruiting women challenging for VAW studies [2], the studies reviewed offered few details about this process. Studies that documented such details utilized community key informants and health workers who were either midwives or lady health visitors for recruitment (Table 1 ). These workers were employed by government institutions or nongovernment agencies and were involved in providing basic health care, primary education, or income-generating opportunities. Ali and BustamanteGavino [26] and Ali and colleagues [20] utilized health workers who belonged to similar community field site where participants were also recruited and were known by the community. In contrast, few studies employed health workers belonging to different field sites [21, 24]. Recruiting women through health workers was preferred in three quantitative [20, 24, 26], a MMR [21], and two qualitative studies reviewed $[28,29]$. None of the other studies documented their recruitment process. Among the studies included in the review, women were either recruited from squatter communities [20, $21,24,26,28]$, public hospitals $[22,23]$, or clinics $[8,25,27]$. Without exception, all the studies reviewed recruited women from low and middle socioeconomic strata of the country $[20,24-26]$. Refusal rates varied from $<1 \%$ [23] to $18.6 \%$ [25] among quantitative studies. 


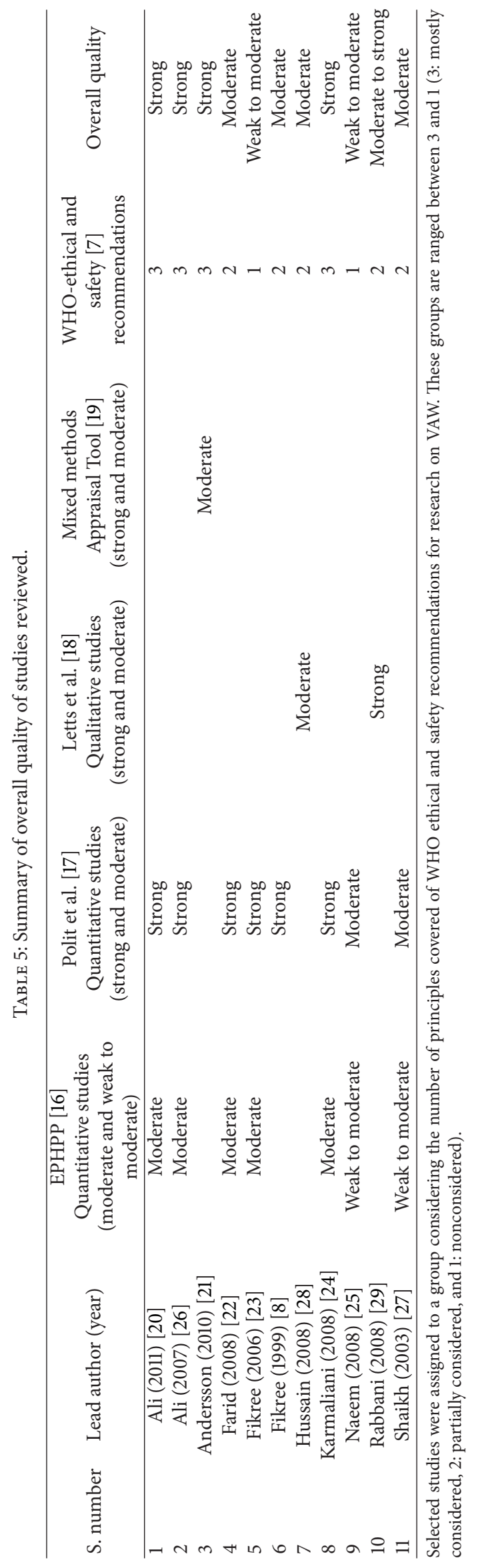


Data Collection. Researchers who study violence and other sensitive subjects are challenged to convince their participants to share their experiences of abuse [4]. Without exception, the administration of an in-person interview was the chosen approach for data collection among all the studies reviewed. In quantitative studies, researchers administered structured questionnaires, whereas within the qualitative studies, an in-depth semi structured interview was conducted. A common pattern among these studies was the use of some form of validated research instrument for data collection (Table 1). The WHO screening instrument modified based on the Pakistani national gender indicator list for VAW, used consistently across three quantitative studies where the primary objective was to measure the prevalence and associated factors of VAW among the sample of urban Pakistani women $[20,22,24]$. Development of an instrument based on focus group discussion (FGD) and its validation through pretesting was also preferred among more than half of the studies reviewed to measure experiences, magnitude, coping, and disclosure to violence [21, 26-29].

The authors of the studies included in the review took special measures to protect participants' confidentiality, privacy, and safety during the process of data collection. Common elements included employment of a female data collector, use of a separate place or room [20, 24, 28, 29], interviewing women only during the day when male members were not present $[21,26]$, or interviewing women outside visiting hours in the case of hospital settings [22]. Three-quarters of the studies reviewed indicated that community health workers were hired and trained to conduct the data collection [2022, 24-26, 29]. Training was mainly focused on prevalence and causes of VAW, vulnerability, ethical considerations, and interviewing skills $[20,24]$. Almost $50 \%$ of the studies explicitly discussed the interviewers' credentials and previous experiences as data collectors [20, 21, 24-26].

In answering the first research question, it is important to determine how the data quality was maintained. Only $40 \%$ of the studies reviewed acknowledged that data quality was maintained through reviewing questionnaires for completeness, revisiting participants in the case of incomplete data, reinterviewing, and double entry of data in the computer $[20,21,24,26,29]$. Due to the low percentage of studies documenting data quality strategies, it could not be clearly assessed.

Analysis. One of the major strengths of a quantitative study is the reporting of relationships between the independent variables and the dependent variable. In this review the quantitative studies applied relevant statistical tests to answer the research question, controlling the confounders and drawing conclusions. Almost all of the quantitative studies achieved their results utilizing descriptive or inferential statistical tests $[8,20-27]$. These tests are appropriate to determine frequencies, where more than one independent variable explains or predicts a dependent variable [17]. Apart from analyzing the prevalence of violence, a common element shared among these studies was inclusion of the demographics of the participants, and the risk and protecting factors associated with violence (Table 1). Since age, socioeconomic status
(SES), and education are strongly associated with women's risk for IPV [4], a large number of studies investigated the relationship among these independent variables and VAW. All quantitative review studies concluded with possible bias in measuring outcomes and study limitations, specifically the generalizability of the results to the entire population. The qualitative studies $[28,29]$ analyzed data through a constant comparative method, a key feature of qualitative research [30]. In addition, the studies reported use of systematic coding schemes, generated themes, and extracted relevant quotations from the study participants. Qualitative studies share measures taken for maintaining study rigor and transferability.

What ethical challenges and subsequent strategies to overcome these challenges are identified in VAW studies from Pakistan?

Due to the nature of the available studies (reports verses research process papers), the challenges were not clearly indicated. Therefore, second research question of the review focuses on measures employed by these studies reviewed to follow the WHO [7] ethical and safety recommendations for research on VAW (Table 2).

More than $50 \%$ of the studies reviewed reported processes related to seeking ethics approval [20-22, 24, 26, $29]$, informed consent $[8,20-22,24-27,29]$, and protecting participants' safety $[20,21,24,26]$. Studies conducted in the community setting committed to recruit only one eligible woman per household, even when other women met study inclusion criteria [20, 24]. This method helps maintain women's safety, as other family members do not know what was discussed with the participant [7]. In a national survey by Andersson and colleagues [21] on barriers to disclosing and reporting violence, it was explicitly mentioned that all the eligible women from selected households were recruited and interviewed simultaneously. However, senior women of the house-hold were interviewed using a less sensitive questionnaire. Women's safety was also assured by providing privacy during interviews and maintaining the confidentiality of the information provided by them. Further actions to prevent potential distress were used by less than half of the studies reviewed $[20,21,24,26]$. These actions included referral for support and handing out educational material related to coping strategies and counseling programs. Moreover, interviewing women about their experiences with violence could be distressful for the interviewers, particularly if they have experienced some form of violence themselves [3]. Only Karmaliani and colleagues [24] explicitly reported consistent practice of interviewer debriefing.

Data safety is a vital element in the WHO [7] recommendations. Keeping data in a locked cabinet with limited access and proper disposal of data at the completion of research are a few of the measures outlined by the WHO [7]. With the exception of Karmaliani and colleagues [24], none of the studies reviewed explicitly reported measures for data safety. It is important to note that more than half of studies reviewed acknowledged following WHO [7] recommendations [8, 20, $21,24,26,28$ ]. Karmaliani et al. [24] was the only study that documented considerations of all elements suggested in the 
guidelines. Hence, variation in reporting of ethical and safety recommendations exists among the studies reviewed.

\section{Discussion}

Results of this critical analysis suggest important considerations for researching the sensitive issue of IPV. In Pakistan, empirical studies conducted in the field of VAW specific to IPV over the past decade are heavily concentrated on small quantitative cross-sectional surveys, whereby women from low and middle socioeconomic urban communities were recruited primarily through random sampling [2025]. The estimate of prevalence of IPV based on the studies reviewed ranges from $44 \%[22,23]$ to $57 \%[20,26]$. The prevalence estimate in Pakistan is similar to that in other Asian countries [31, 32]. Nevertheless, with variations in prevalence rate it is hard to be confident that the estimates are generalizable to the national level, especially given the small and special nature of the sample as acknowledged by many studies reviewed. The literature suggests that studies that are smaller in scope but dedicated primarily to the issues of domestic violence and IPV demonstrate higher estimates compared to government-led national surveys [33]. Possible reasons are the use of a less sophisticated sampling strategy and innovative ways of asking relevant questions about the nature of VAW [34]. Brush [33] shared an analogous idea that a survey with a wider focus is inevitably restricted in time and the effort required to elicit responses. Nevertheless, exploring the experiences of violence in a national survey design for other purposes but specific to violence should meet the ethical and methodological requirement for research on VAW [7]. In the absence of Pakistan's national survey data on VAW, the estimated findings from the review studies could not be compared.

The sampling strategy used by most researchers in the studies reviewed is simple random, which is considered the most common technique used in VAW studies [35]. Though randomization could reduce the possibility of selection bias and maximize the internal and external validity [17], the question arises if abused women are more or less likely than nonabused women to participate [4]. Researchers debate whether victims of abuse are more or less motivated than nonabused women to participate in studies concerning violence $[3,36]$. An important observation from the study by Andersson and colleagues [21] is that eligible women may want to be interviewed, but the senior or other members of the household refuse to allow them. Studies by colleagues of Fikree et al. [23] and Farid et al. [22] excluded women admitted for abortion or pregnancy-related complications, and Naeem et al. [25] excluded women reporting severe illness. These omissions are significant in underestimating the total burden of violence in general and during pregnancy in particular.

Studies reviewed demonstrated high response rates, due to known and trusting relationships with the health workers who were employed for recruitment and data collection. Studies by Ali and Bustamante-Gavino [26] and Ali and colleagues [20] justify the high prevalence found in their studies as due to the fact that women were recruited by the health workers, who were known to the participants and had developed rapport, making the disclosure of violence experiences possible. Likewise, evidence gathered from the qualitative studies suggests that seeking assistance of community key informants was useful, firstly to identify abused women and secondly to motivate them to become study participants $[28,29]$. WHO discourages interviewers from conducting interviews in the home setting because of safety and confidentiality [7]. Considering the fact that Pakistani cultural norms make access for strangers into the household difficult [11], the aforementioned discussion causes the author to wonder if the involvement of individuals (such as health workers or community key informants) known to potential participants in the research process (specifically as data collectors) would improve participation and disclosure, or whether it would make the abused women more vulnerable through increased visibility.

One of the special features of the WHO recommendations is the inclusion of measures to ensure participant' and interviewer safety and emotional support including, privacy during the interview, special training in conducting sensitive interviews, gender of the interviewer, and referral for care [7]. This analysis reveals that in studies where participant safety was ensured, some required measures were applied. Selecting more than one eligible participant per household may impact participant safety and offer challenges with achieving adequate response rates. For example, when only one woman in each household is interviewed and the interview is conducted in private, it cannot be assumed that other household members do not know the subject of the interview and/or cannot overhear the discussion [3]. There is also the possibility of interference by family members or forced disclosure of the information provided by the participant. The literature suggests that presence of a household member and/or the perpetrator will reduce the reporting of violence $[2,35]$. Switching interviews with a fake questionnaire in case of interruption or simultaneously undertaking an interview with other family members using a less sensitive questionnaire may guard participant safety [2]. Several investigators discouraged their study participants from discussing details of the interview with anyone $[21,24]$.

Scholars, particularly feminist researchers working on improving the methodological rigor of violence studies, recommend a series of strategies to ensure safety and enhance disclosure [37]. One such strategy is the way the interview question is framed, worded, and ordered and number of times it is asked of the participants. For example, the study by Andersson and team [21] began by exploring broad questions relevant to family norms and women's opinions on them, before moving into women's experiences or risk of experiencing violence. Qualitative studies centered their questions on participant's experiences of abuse $[28,29]$. In addition, providing participants with multiple opportunities and time to disclose may improve recollection of the past, build trust to speak about violence, and demonstrate a genuine interest and willingness to listen [33]. This is evident in the Karmaliani and team [24] study, where participants were given extra support and offered a glass of water, tissues, and extra time to respond to sensitive questions. A low estimate of sexual violence 
was reported by Farid and colleagues [22], where study participants were asked only once about their experiences of sexual abuse.

The discussion above highlights the importance of promoting trust and safety when interviewing about VAW. Nevertheless, cultural norms and practices can greatly impact methodological rigor, including response rates, when studying this highly stigmatized, traumatized population. While different interviewing methods may have implications for safety and response rate, it is the researcher's responsibility to assure participant safety. Given the absence of details regarding such questioning techniques among the studies reviewed, no clear conclusion regarding the best strategies can be made. It is possible, that the use of selected and culturally validated instruments may have an impact on disclosure. WHO recommends the use of pretested and piloted research instruments [7].

In light of the above challenges it is prudent to explore training opportunities for data collection. WHO places emphasis on the careful selection and training of interviewers who are able to confront their own fears and stereotypes regarding abuse [7]. In this review, researchers who provided training documented that the training focused primarily on the significance of VAW. It could not be determined if the training incorporated other measures, such as overcoming biases among interviewers and maximizing disclosure. There is some evidence that using female interviewers [37] with previous experience in the field of psychology, sociology $[25,26]$, or other sensitive areas older than 20 years of age [21] may enhance data collection. These characteristics may also be protective for interviewers. That is, although women may welcome the opportunity to talk about their abuse experiences, the process can be deeply distressing for the interviewers as well as the participants [3, 4]. The WHO [7] recommendations for addressing ethical and safety issues in conducting research on violence strongly urge researchers to undertake such studies only if they are able to ensure minimal safety standards, including referrals for the participants and support for the interviewers [4]. Debriefing and referral were evident among some reviewed studies; however, the effectiveness of the measures was not reported and therefore cannot be analyzed.

Finally, one of the major elements of the WHO guidelines is to build upon the current methodologically sound research in the area of VAW studies [7]. This may be achieved through enhancing the richness and depth of the data. When addressing improvements in the methodological rigor of VAW studies, some authors argue that studies that only measure prevalence do not depict a complete picture of victims' suffering [35]. Rather, studies should analyze the correlation and possible casual pathways between variables such as socioeconomic status, victim, and perpetrator level of education and information related to family $[4,5]$. The analysis of these relationships is provided by the studies included in the review.

In summary, a lack of information in published studies challenged the authors when determining the methodological quality and credibility of the selected studies for this integrative review. Nevertheless, it is recommended that methodological quality of violence studies be assessed by a comprehensive critical appraisal and that the WHO ethical and safety recommendations be used to supplement the general guidelines to measure methodological quality [7]. This strategy will strengthen methodological consistency, promote participants and researchers safety, and develop best practice guidelines in conducting studies concerning VAW.

\section{Recommendations for Research, Practice, and Education}

Given the complexities in conducting research on VAW, there are multiple ways through which this review is relevant to nursing science. As nurses are now moving beyond traditional roles and counteracting violence at primary, secondary, and tertiary levels of care [38], a pluralist approach in nursing research, practice, and education is needed.

\section{Research}

Despite the methodological limitations and given the absence of a population-based survey in Pakistan, these small crosssectional surveys and limited qualitative studies are indispensable sources of data regarding the state of VAW research. There are several ways that research focusing on VAW can be further developed. First, sampling frames need to be enhanced to include populations from rural settlements, where $70 \%$ of the Pakistani population resides [39]. The review studies were limited to the low and middle socioeconomic strata of urban settlement of the country. There are no known studies of VAW conducted on the upper socioeconomic strata of Pakistan. Examining variables more prevalent in this group and among rural populations may provide an evidential basis for further understanding of VAW in Pakistan.

Although data collection by health workers increases the likelihood of disclosure, it may have a negative effect in terms of confidentiality, if proper training is not employed. The victim may feel more vulnerable and not reveal the true experiences of abuse when in a known relationship with the interviewer. An area that is rarely considered is how women participants in VAW studies feel about themselves and their environment after the interview [3]. Retrospective research is needed to identify whether sharing interview details with others and employment of known interviewers would place women at risk of further abuse. As well it is important to understand how stress levels of women participants are affected this sensitive research [3].

Finally, determining the utilization and effectiveness of referral services to seek support and the risks and benefits of debriefing for interviewers would be another area of vital interest for HCPs, policy makers, and researchers. Considering the nature of VAW, where health researchers require other organizations to perform advocacy and related services for abuse, it is worthwhile to conduct collaborative research with NGOs, health policy makers, the criminal justice system, and the media [3]. 
6.1. Nursing Practice. The health care setting has been identified as one of the best contexts in which VAW can be identified [40]. However, there is no scientific evidence of the benefit of universal screening for violence in the health care setting, and this issue is actually controversial among researchers [41]. Nevertheless, international health organizations do recommend that health care practitioners follow a protocol to identify and manage abused victims [42]. It is important that nurses recognize and apply skills in obtaining detailed and reliable data, as this is a first step in understanding the dynamics of violence in order to establish preventive and relevant interventions [43]. Nurses need to be educated and trained not only to recognized abuse women, but also to utilize referral pathways and other supportive mechanisms. Aside from direct care, many HCPs are engaged in VAW studies. This area is considered a national research priority for emergency nurses [44]. Nurses should exercise caution when engaging in VAW research to overcome the methodological and ethical challenges and to correctly interpret their findings.

6.2. Nursing Education. The results of this integrative review should encourage nurses involved in professional education to strengthen nursing curricula to include violence-specific knowledge and skills in conducting research in such contexts to prepare future nurses to address the methodological issues [45]. Evidence-based data suggest integrating violence content and experiential learning opportunities in nursing curricula positively affects nurses' responses to violence issues [46]. Woodtli and Breslin [47] emphasize the importance of preparing nursing students to follow a multidisciplinary approach, thus enabling sensitive, effective quality nursing care. Thus, in keeping with WHO [7], it is recommended that VAW researchers draw conclusions that are focused on interventions that benefit women.

\section{Conclusion}

The findings of this integrative review indicate that studies focusing on VAW in Pakistan are highly sensitive to a number of methodological factors and traditional cultural norms towards women. Such studies may jeopardize women's and interviewers' safety and is a major threat to study rigor. Good quality research on VAW is one of the major components in the design of interventions that can end this issue [3]. The review encourages researchers to take the required actions to improve the robustness of VAW studies. Moreover, findings need to be interpreted in the context of local meaning in order to benefit women.

\section{Limitations of the Review}

Although this review focused on the methods of VAW studies conducted in Pakistan, the paper does not include how VAW is defined and measured by these review studies because of its wide scope. Secondly, due to a lack of published reports related to the VAW research process among Pakistani women, it was challenging for the author to speculate whether absence of relevant information was because of publication space, or whether lack of description should be interpreted as poor methodological quality. A final limitation of this review was the limited number of good quality studies from Pakistan on VAW. It is possible that different findings may emerge as stronger methodological studies and papers focusing on more rigorous research processes become available.

\section{Conflict of Interests}

The authors declare that there is no conflict of interests regarding the publication of this paper.

\section{References}

[1] World Health Organization, "World report on violence and health," 2002, http://whqlibdoc.who.int/hq/2002/9241545615 .pdf.

[2] N. Andersson, A. Cockcroft, N. Ansari et al., "Collecting reliable information about violence against women safely in household interviews: experience from a large-scale national survey in South Asia," Violence Against Women, vol. 15, no. 4, pp. 482496, 2009.

[3] R. Jewkes, C. Watts, N. Abrahams, L. Penn-Kekana, and C. García-Moreno, "Ethical and methodological issues in conducting research on gender-based violence in Southern Africa," Reproductive Health Matters, vol. 8, no. 15, pp. 93-103, 2000.

[4] M. Ellsberg, L. Heise, R. Peña, S. Agurto, and A. Winkvist, "Researching domestic violence against women: methological and ethical considerations," Studies in Family Planning, vol. 32, no. 1, pp. 1-16, 2001.

[5] M. Piispa and M. Heiskanen, "Violence against women survey in Finland; Methodology and experiences," Statistical Journal of the United Nations Economic Commission for Europe, vol. 22, no. 3-4, pp. 255-263, 2005.

[6] M. D. Schwartz, "Methodological issues in the use of survey data for measuring and characterizing violence against women," Violence Against Women, vol. 6, no. 8, pp. 815-838, 2000.

[7] World Health Organization, "Putting women first: Ethical and safety recommendations for research on domestic violence against women. Geneva: Global program on evidence for health policy," 1999, http://www.who.int/gender/violence/ womenfirtseng.pdf.

[8] F. F. Fikree and L. I. Bhatti, "Domestic violence and health of Pakistani women," International Journal of Gynecology and Obstetrics, vol. 65, no. 2, pp. 195-201, 1999.

[9] A. Raj and J. G. Silverman, "Intimate partner violence against South Asian women in greater Boston.", Journal of the American Medical Women's Association, vol. 57, no. 2, pp. 111-114, 2002.

[10] E. Gracia, "Unreported cases of domestic violence against women: towards an epidemiology of social silence, tolerance, and inhibition," Journal of Epidemiology and Community Health, vol. 58, no. 7, pp. 536-537, 2004.

[11] S. Douki, F. Nacef, A. Belhadj, A. Bouasker, and R. Ghachem, "Violence against women in Arab and Islamic countries," Archives of Women's Mental Health, vol. 6, no. 3, pp. 165-171, 2003.

[12] U. Niaz, "Violence against women in South Asian countries," Archives of Women's Mental Health, vol. 6, no. 3, pp. 173-184, 2003. 
[13] UN General Assembly, "Declaration on the elimination of violence against women," A/RES/48/104, 1993, http://www.unhcr .org/refworld/docid/3b00f25d2c.html.

[14] R. Whittemore and K. Knafl, "The integrative review: updated methodology," Journal of Advanced Nursing, vol. 52, no. 5, pp. 546-553, 2005.

[15] World Health Organization, Protocol for WHO Multi-Country Study on Women's Health and Domestic Violence, World Health Organization, Geneva, Switzerland, 1997, http://www.who.int/ gender/documents/Interviewer_training.pdf.

[16] Effective Public Health Practice Project, "Quality assessment tool for quantitative studies," http://www.ephpp.ca/PDF/QADictionary_Sep2011.pdf.

[17] D. Polit, C. T. Beck, and B. P. Hungler, Essentials of Nursing Research: Methods, Appraisal and Utilization, Lippincott, Philadelphia, Pa, USA, 6th edition, 2006.

[18] L. Letts, S. Wilkins, M. Law, D. Stewart, J. Bosch, and M. Westmorland, "Critical review form-Qualitativestudies (version 2.0)," 2007, http://www.srs-mcmaster.ca/Portals/20/ pdf/.../qualreview_version2.0.pdf.

[19] P. Pluye, E. Robert, M. Cargo et al., "Proposal: a mixed methods appraisal tool for systematic mixed studies reviews," http://mixedmethodsappraisaltoolpublic.pbworks.com, http://www.webcitation.org/5tTRTc9yJ.

[20] T. S. Ali, N. Asad, I. Mogren, and G. Krantz, "Intimate partner violence in urban Pakistan: prevalence, frequency, and risk factors," International Journal of Women's Health, vol. 3, no. 1, pp. 105-115, 2011.

[21] N. Andersson, A. Cockcroft, U. Ansari et al., "Barriers to disclosing and reporting violence among women in pakistan: Findings from a national household survey and focus group discussions," Journal of Interpersonal Violence, vol. 25, no. 11, pp. 1965-1985, 2010.

[22] M. Farid, S. Saleem, M. S. Karim, and J. Hatcher, "Spousal abuse during pregnancy in Karachi, Pakistan," International Journal of Gynecology and Obstetrics, vol. 101, no. 2, pp. 141-145, 2008.

[23] F. F. Fikree, S. N. Jafarey, R. Korejo, A. Afshan, and J. M. Durocher, "Intimate partner violence before and during pregnancy: experiences of postpartum women in Karachi, Pakistan," Journal of the Pakistan Medical Association, vol. 56, no. 6, pp. 253-257, 2006.

[24] R. Karmaliani, F. Irfan, C. M. Bann et al., "Domestic violence prior to and during pregnancy among Pakistani women," Acta Obstetricia et Gynecologica Scandinavica, vol. 87, no. 11, pp. 11941201, 2008.

[25] F. Naeem, M. Irfan, Q. A. Zaidi, D. Kingdon, and M. Ayub, "Angry wives, abusive husbands: Relationship between domestic violence and psychosocial variables," Women's Health Issues, vol. 18 , no. 6, pp. 453-462, 2008.

[26] T. S. Ali and I. Bustamante-Gavino, "Prevalence of and reasons for domestic violence among women from low socioeconomic communities of Karachi," Eastern Mediterranean Health Journal, vol. 13, no. 6, pp. 1417-1426, 2007.

[27] M. A. Shaikh, "Is domestic violence endemic in Pakistan: perspective from Pakistani women," Pakistan Journal of Medical Sciences, vol. 19, no. 1, pp. 23-29, 2003.

[28] R. Hussain and A. Khan, "Women's perceptions and experiences of sexual violence in marital relationships and its effect on reproductive health," Health Care for Women International, vol. 29, no. 5, pp. 468-483, 2008.

[29] F. Rabbani, F. Qureshi, and N. Rizvi, "Perspectives on domestic violence: case study from Karachi, Pakistan," Eastern Mediterranean Health Journal, vol. 14, no. 2, pp. 415-426, 2008.
[30] J. Creswell, Research Design: Qualitative, Quantitative, and Mixed Methods Approaches, Sage, Thousand Oaks, Calif, USA, 2009.

[31] L. M. Bates, S. R. Schuler, F. Islam, and M. K. Islam, "Socioeconomic factors and processes associated with domestic violence in rural Bangladesh," International Family Planning Perspectives, vol. 30, no. 4, pp. 190-199, 2004.

[32] J. G. Silverman, M. R. Decker, N. Saggurti, D. Balaiah, and A. Raj, "Intimate partner violence and HIV infection among married Indian women," Journal of the American Medical Association, vol. 300, no. 6, pp. 703-710, 2008.

[33] L. D. Brush, "Violent Acts and injurious outcomes in married couples: methodological issues in the national survey of families and households," Gender and Society, vol. 4, no. 1, pp. 56-67, 1990.

[34] H. Johnson and V. F. Sacco, "Researching violence against women: Statistics Canada's National survey," Canadian Journal of Criminology, vol. 37, no. 3, pp. 281-304, 1995.

[35] V. Jaquier, H. Johnson, and B. S. Fisher, "Research methods, measures, and ethics," in Sourcebook on Violence against Women, SAGE, 2nd edition, 2011.

[36] J. J. Haugaard and R. E. Emery, "Methodological issues in child sexual abuse research," Child Abuse and Neglect, vol. 13, no. 1, pp. 89-100, 1989.

[37] J. C. Campbell and J. A. Dienemann, "Ethical issues in research on violence against women," in Sourcebook on Violence against Women, C. M. Renzetti, J. L. Edleson, and R. K. Bergen, Eds., pp. 57-72, Sage, Thousand Oaks, Calif, USA, 2001.

[38] M. A. Woodtli, "Nurses' attitudes toward survivors and perpetrators of domestic violence," Journal of Holistic Nursing, vol. 19, no. 4, pp. 340-359, 2001.

[39] World Health Organization, "Country cooperation strategy for WHO and Pakistan 2005-2009," http://www.who.int/ countryfocus/cooperation_strategy/ccs_pak_en.pdf.

[40] R. E. Davis and K. E. Harsh, "Confronting barriers to universal screening for domestic violence," Journal of Professional Nursing, vol. 17, no. 6, pp. 313-320, 2001.

[41] J. Ramsay, J. Richardson, Y. H. Carter, L. L. Davidson, and G. Feder, "Should health professionals screen women for domestic violence? Systematic review," The British Medical Journal, vol. 325, no. 7359, pp. 314-318, 2002.

[42] J. A. Gazmararian, R. Petersen, A. M. Spitz, M. M. Goodwin, L. E. Saltzman, and J. S. Marks, "Violence and reproductive health: current knowledge and future research directions," Maternal and Child Health Journal, vol. 4, no. 2, pp. 79-84, 2000.

[43] J. C. Campbell, J. H. Coben, E. McLoughlin et al., "An evaluation of a system-change training model to improve emergency department response to battered women," Academic Emergency Medicine, vol. 8, no. 2, pp. 131-138, 2001.

[44] E. W. Bayley, S. L. MacLean, P. Desy, and M. McMahon, “ENA’s Delphi study on national research priorities for emergency nurses in the United States," Journal of Emergency Nursing, vol. 30, no. 1, pp. 12-21, 2004.

[45] J. C. Campbell, "A review of nursing research on battering," in Violence against Women, C. M. Sampselle, Ed., Hemisphere, New York, NY, USA, 1992.

[46] M. A. Woodtli, "Domestic violence and the nursing curriculum: tuning in and tuning up," Journal of Nursing Education, vol. 39, no. 4, pp. 173-182, 2000.

[47] M. A. Woodtli and E. Breslin, "Violence-Related Content in the Nursing Curriculum: a National Study," Journal of Nursing Education, vol. 35, no. 8, pp. 367-374, 1996. 


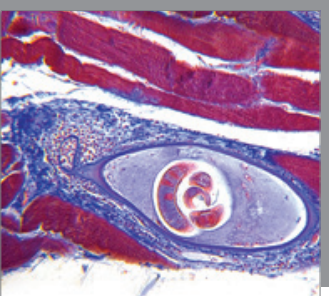

Gastroenterology

Research and Practice
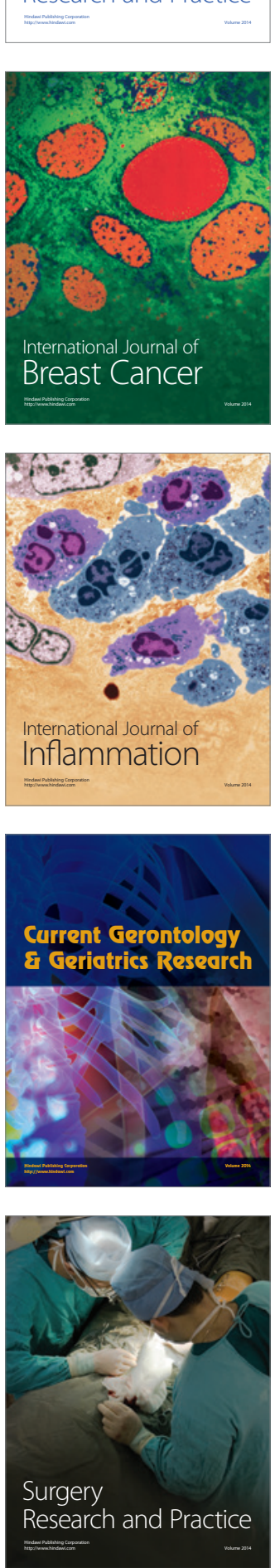

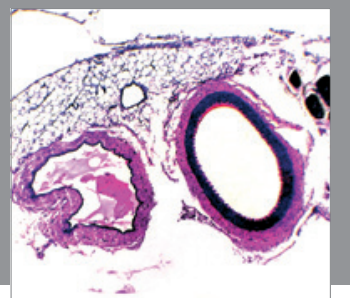

International Journal of Hypertension
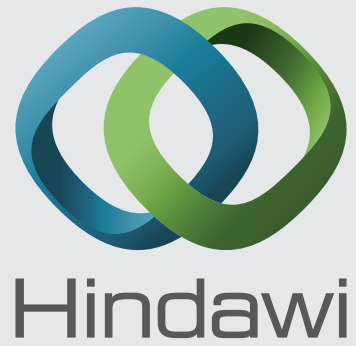

Submit your manuscripts at http://www.hindawi.com
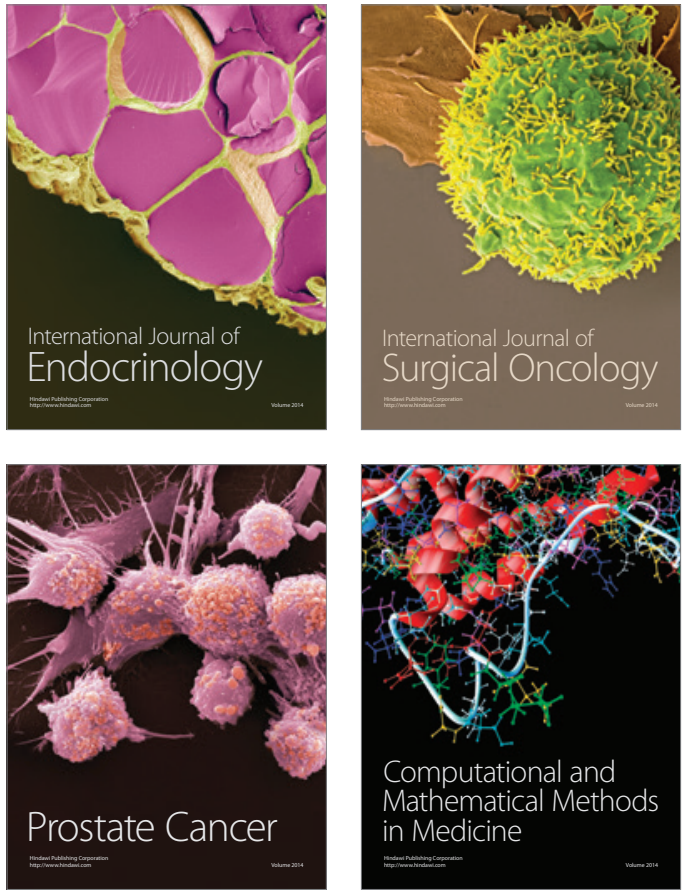
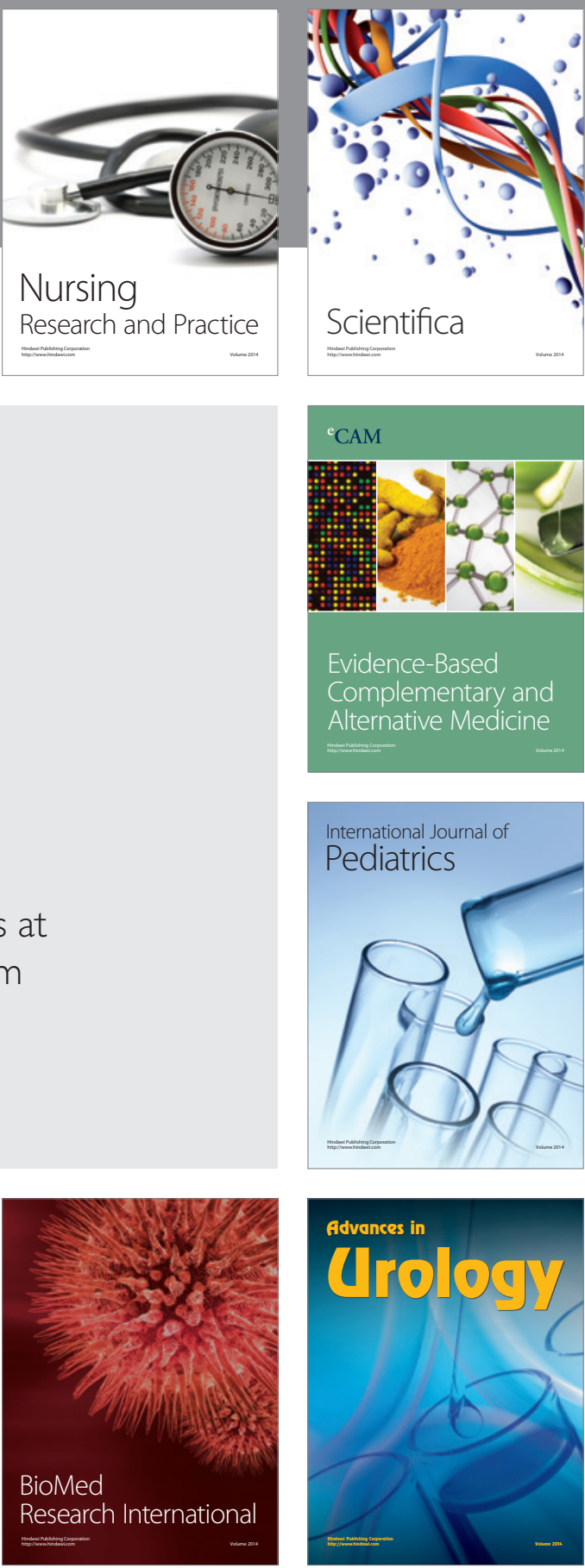

Nursing

Research and Practice

Scientifica

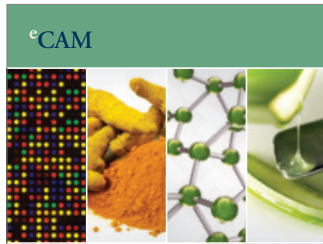

Evidence-Based

Complementary and Alternative Medicine
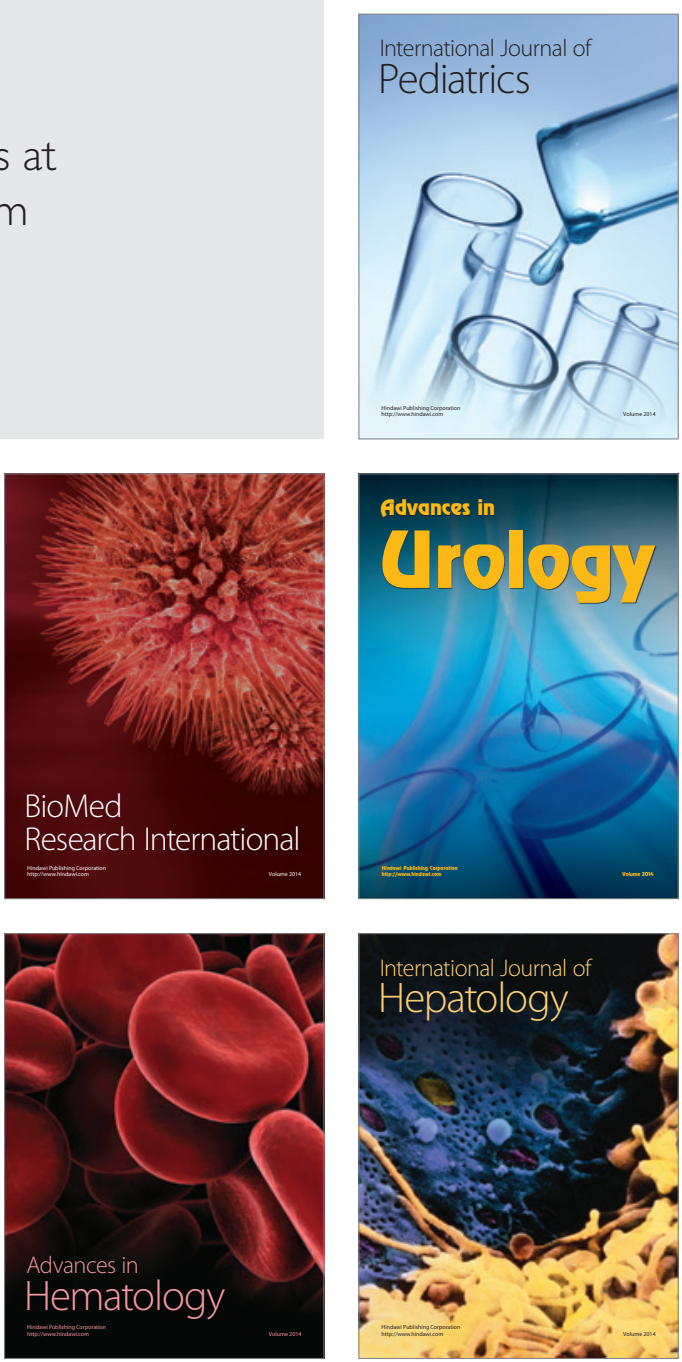